\title{
ARCHIVO HISTÓRICO
}

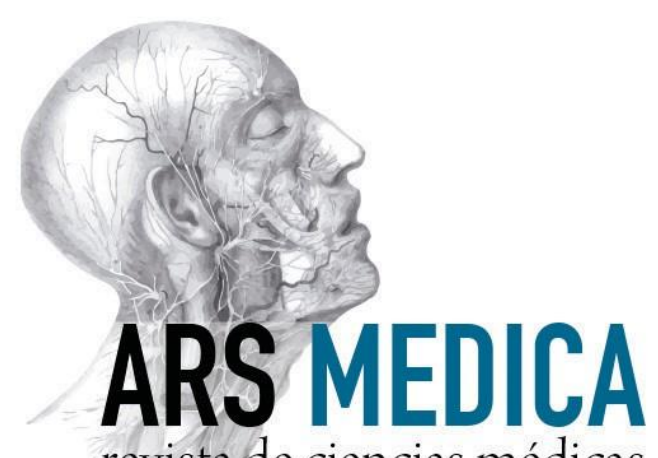

revista de ciencias médicas

El presente artículo corresponde a un archivo originalmente publicado en Ars Medica, revista de estudios médicos humanísticos, actualmente incluido en el historial de Ars Medica Revista de ciencias médicas. El contenido del presente artículo, no necesariamente representa la actual línea editorial. Para mayor información visitar el siguiente vínculo: http://www.arsmedica.cl/index.php/MED/about/su bmissions\#authorGuidelines 


\title{
Evitar la distanasia tecnocrática. Objetivos de los cuidados paliativos
}

\author{
Dr. Fernando Lolas Stepke \\ Profesor Titular de la Universidad de Chile \\ Director Unidad de Bioética \\ Organización Panamericana de la Salud
}

\begin{abstract}
Algunas precisiones
El probable origen etimológico de la voz "paliativo" en la palabra latina pallium, que significa manto o cubierta, puede implicar que un cuidado paliativo o una medicina paliativa solamente "cubren" (o "encubren") síntomas sin remover sus causas. La medicina científiconatural ha estimado siempre que el proceder técnico en la sanación o la curación de las dolencias consiste en descubrir qué las causa y "solucionar" la enfermedad atacando su etiología: destruir el microbio, remover el tumor, restablecer la normalidad de los indicadores fisiológicos (Lolas, 1992). Cuando la causa no se puede establecer (como a veces en la psiquiatría) o no se puede eliminar (como en la enfermedad crónica y terminal) pareciera que algo falta en el proceso técnico. Se produce perplejidad, insatisfacción, sensación de insuficiencia. "Paliar" significa, en este contexto, una actividad adventicia, marginal, de segunda clase, pues en el fondo significa ocultar, distraer, no actuar científicamente.
\end{abstract}

De allí que la expresión "medicina paliativa" sea tan contraproducente. La medicina, en tanto locus de la técnica reglada, no puede permitir -salvo que renuncie a su estatuto disciplinariouna acción insuficiente como simplemente la de atenuar, cubrir. ¿Qué aportaría un médico que solamente encubre sin efectivamente "tratar", esto es, intervenir con decisión y conocimiento? Sería la irrelevancia misma. De allí que mucho de lo que se consigue con tecnificar lo paliativo es conducir a la futilidad médica, al encarnizamiento terapéutico, como si se intentara, con un activismo intenso, reivindicar el papel de la técnica.

Para no crear esta innecesaria tensión semántica es conveniente usar la expresión "cuidados paliativos". No alude ella a medicina en un sentido técnico-profesional. Permite reconocer la importancia de lo simplemente humano, aquello que se redescubre cuando, por así decir, se instala la reflexión y la acción, en un "más allá" de la técnica. Se redescubre la vulnerabilidad y la finitud que las "distracciones tecnológicas" permanentemente nos ocultan. Los textos "serios" sobre cuidados paliativos se extienden sobre manejo de hidratación, sedación, nutrición, normas generales de cuidado, agregando que el calor humano y la compasión han de tener un sitio en la práctica, pero a menudo sin explicitar cómo, cuándo, por qué y, lo más importante, por quién.

Hay que reconocer que los cuidados paliativos corren el riesgo de rutinizar la compasión y la solidaridad humanas, movimientos del alma que difícilmente se dejan estandarizar, provocar o inducir. Las emociones de quienes se involucran como "dadores de cuidado" (caregivers), sean profesionales o profanos, significan esfuerzo, causan desgaste y deben ser reconocidas como factores de la práctica social paliativa. El día del cuidador (generalmente "la" cuidadora, por la tradicional asignación del cuidado al género femenino en las culturas humanas) es un "día 
largo", no de 24 sino de 36 y más horas. La vocación a veces no basta, el burn-out se hace sentir, los derechos del cuidador en tanto participante de un proceso de construcción de calidad de vida podrían olvidarse.

De allí que simplemente describir qué debe hacerse (en el sentido técnica y políticamente correcto de este aserto) no basta. Es menester indagar por los condicionantes sociales, culturales, económicos que permiten aceptar la existencia de ciertas formas de cuidado que no remueven causas sino solamente acompañan. Como a menudo este acompañamiento es un acompañamiento para la muerte (aunque no es necesario que la voz "paliativo" se entienda solamente en el estadio terminal), la postura frente a la muerte (tanatofobia negadora o tanatofilia aberrante), la infraestructura asistencial y valórica de una sociedad, la formación profesional y el clima moral y religioso de una comunidad deban ser tenidos en cuenta. La "medicalización de la muerte" no puede ser la única forma aceptable de terminar la vida. Mas tampoco puede ser la negación total de la técnica o la simplista afirmación de "autonomías" ilusorias o "episeguridades" superficiales y falsas, como las que ofrecen los seguros de la casa, el automóvil, el patrimonio, el cuerpo o la vida. La combativa postura antimédica con que a veces se asocia lo paliativo, la indiferencia o el desdén de la profesión médica, el rechazo de la industria aseguradora, la paradójica insistencia en "hacer todo lo posible" restando a veces dignidad a la muerte, son algunos de los hitos en que debe detenerse la reflexión.

\section{Dificultades para conceptualizar los cuidados paliativos}

La tabuización de la muerte, las esperanzas en el progreso indefinido de las técnicas asociadas a la medicina, las emociones que despierta la agonía humana son algunos de los factores que complican la discusión ética sobre los cuidados paliativos y el trato que se da a los pacientes críticos y terminales (Lolas, 2000, 2004).

Por de pronto, nadie desea oír hablar de la muerte, propia o ajena. Menos aún, discutir en qué consiste la dignidad de las personas bajo circunstancias excepcionales o habitualmente reprimidas como escenario, cuales son las del moribundo o del enfermo sin remisión posible. De allí que nos enfrentemos a un tópico que deja de ser técnico para entrar de lleno en el campo de los deseos y las emociones.

Abandonar el tratamiento cuando la Naturaleza había hablado fue precepto para el médico hipocrático. La anánke -por oposición a la tyche-impedía al médico intervenir, con el fin de no contravenir el dictamen de lo natural y por ende de lo moralmente bueno. La esperanza en la técnica y en las tecnologías (fundamento racional de las técnicas y sus contextos de aplicación) es en buena medida creación de los investigadores y la industria. Callahan habla de "falsas esperanzas" para aludir al infundado deseo de que la enfermedad y la muerte sean erradicadas de la vida humana (Callahan, 1998).

Sin duda alguna, la compasión y la caridad son virtudes que influyen sobre el trato que esperamos dar a los enfermos o recibir cuando enfermamos. La idea de no intentar todo lo imaginable es repulsiva a la imaginación moral de casi todas las personas en un entorno cristiano. De allí que un movimiento automático, prerreflexivo, de la mayor parte de las personas consista en repudiar cualquier sugerencia de interrumpir los cuidados en un paciente crítico o terminal o de no hacer nada que garantice descubrir 
causas y subsanarlas. A menudo se ignora que el activismo técnico sirve solamente como distractor que mitiga la angustia y produce la sensación, en la conciencia, de que se hizo "todo lo posible". Llegar a esa convicción de lo inevitable por el difícil camino de la inutilidad comprobada hace sufrir y causa sufrimiento. El papel de la deliberación bioética -aquí en un registro interaccional, dialógico y transdisciplinar- es precisamente anticipar escenarios y producir aquello que sea apropiado a la circunstancia, bueno para los agentes morales y justo para la sociedad y las personas.

El resultado de estas tres influencias, la muerte como tabú inmencionable (tanatofobia), la tecnología como última esperanza y la compasión como emoción, es una constante inquietud cuando se abordan los problemas que plantea el final de la vida. De hecho, ellos fueron cruciales en el establecimiento de la bioética como disciplina (Drane, 1999) y es un campo en el cual paradigmáticamente se enfrenta la ética de las convicciones con la ética de la responsabilidad, en el sentido que les dio Max Weber.

\section{La muerte es problema para los vivos}

Un buen principio de definición de los cuidados paliativos lo proporciona Manzini (1997), cuando dice: "Originados en el llamado "movimiento hospice", consisten en el cuidado activo y total de los pacientes cuya enfermedad no responde al tratamiento curativo. Consideran al paciente y a su grupo familiar como objeto y sujeto de los cuidados, tratando de satisfacer sus necesidades físicas, psíquicas, espirituales y sociales”.

En esta definición hay muchos puntos de interés, desde la alusión al movimiento que inaugurara Cecily Saunders en 1967 bajo el nombre hospice hasta la idea de cuidado activo y total en que intervienen tanto los médicos y el personal sanitario como los familiares y cercanos del paciente. Habría que recordar que no se trata solamente de un problema técnico - de allí que la palabra interdisciplinario no sea la mejor- sino esencialmente una tarea de humanidad respetuosa de otra humanidad sufriente. De allí que la clásica distinción entre "expertos" y "profanos" se difumine y que ante el hecho irreversible de la muerte próxima tanto valga el saber científico como el compasivo acompañamiento. Tal vez la noción clave sea la de "cuidador" genérico, más allá de las distinciones debidas a educación, conocimientos, experiencia o proximidad al sufriente.

Las metas clásicas de la medicina (curar y sanar), reflejadas en el clásico "papel de enfermo" (sick role) con que la sociología clásica describió las relaciones entre médicos y pacientes, no pueden cumplirse en dos condiciones: la primera es la enfermedad crónica, pues allí no existe la curación ad integrum sino a lo sumo la restitutio ad integritatem, es decir, el retorno a una vida aparentemente normal; la segunda es precisamente la enfermedad que amenaza la vida, la condición de paciente terminal (que no es lo mismo que paciente crítico). Las tradicionales obligaciones y derechos de "ser paciente" se suspenden, del mismo modo que se ponen en entredicho muchos de los modos habituales de proceder por parte de los profesionales. Librados a la responsabilidad de tomar decisiones nunca plenamente satisfactorias, suelen optar por el "mal menor" o recurrir a las nociones de tratamiento proporcionado y desproporcionado y de "doble efecto" cuando deben dar cuenta de sus actos.

Tal vez uno de los principales problemas sea el de definir la muerte. Tanto el principio como el fin de la vida suelen producir discrepancias de naturaleza doctrinaria más que técnica. Porque la muerte, en el plano microcósmico de los cromosomas y los genes, no existe: la vida es un flujo 
continuo. Tampoco existe en los agregados sociales, las comunidades que siguen existiendo aunque desaparezcan algunos de sus miembros. La muerte personal es la única que tiene significado en el plano humano. Es la que sentimos y lloramos. Las otras son muertes impersonales, simple renovación de la naturaleza (Lolas, 1997).

Se conocen las dificultades para definir el "momento" de la muerte. También las construcciones jurídico-médicas necesarias para permitir ciertas intervenciones ("muerte cerebral" y trasplantes, por citar un ejemplo). Aunque definir el momento exacto de la muerte constituya problema, más problemático es definir cuando una vida se extinguirá sin posibilidad de recuperación. Un terror engendrado por la tecnología es justamente quedar condenado a la vida o sufrir una muerte crónica, una mala muerte, o, como también suele decirse, una "distanasia" a manos de diligentes tecnócratas o juristas empecinados en defender un proceder profesional que satisface el purismo procedimental sin considerar los deseos de las personas. Hay varias formas de distanasia (Pessini, 2004), pero la más deletérea es la "distanasia tecnocrática", aquella engendrada por el activismo y encarnizamiento con que se atenúa la angustia del técnico abismado ante su propia inutilidad o presionado por emociones incontrolables de quienes desean preservar a un ser querido. Provocativamente puede decirse que a veces tales deseos no se manifiestan en pro del que sufre sino de los que sobrevivirán. Muchas demandas de intervención total no se hacen pensando en el bienestar de quien muere sino en el de quienes se satisfacen con su existencia, al modo de una presencia aliviadora pero que sirve intereses egoístas de los sobrevivientes, aunque nunca sean admitidos.

Hay que recordar la poética dádiva que recibió el centauro Quirón, expuesto al sufrimiento de una herida incurable: fue la "mortalidad", la posibilidad de poner fin al sufrimiento, el don de morir. A veces, la vida de mala calidad y sin esperanzas, hace clamar por el alivio de la muerte. Descartada una condición patológica (depresión, por ejemplo), se puede entender ese deseo y compadecer a quienes llegan a tenerlo. Lo que se decida debe tener la densidad de lo justo, de lo propio y de lo bueno, producir símbolos positivos, generar identidades satisfactorias. Saber que se está haciendo lo que se debe es sin duda la satisfacción más plena de cualquier imperativo categórico y la conclusión más completa de ese diálogo con la propia conciencia que es la marca de un profesional o una persona de bien.

\section{Los contextos: valórico, social, cultural, económico, administrativo.}

Establecer cuidados paliativos como parte de la oferta de servicios sanitarios en una comunidad parece de una obviedad simple. Sin embargo, la concreción no se logra si antes no hay un diálogo social amplio, para iniciar el cual se requiere emoción. Emoción, esto es, movimiento causado por alguna situación espectacular, alguna necesidad sentida, algún ejemplo inolvidable. Trasplantar el éthos del hospice al estilo de los países anglosajones a la realidad latinoamericana sin análisis sería impropio. La humanidad no es una y la misma cuando de vivir y morir se trata. Lo mudable es lo estable en la naturaleza humana.

Lo económico, en tanto racionalidad y guía de lo usual, debe ser tenido en cuenta. Hay paradojas en los sistemas de salud. Se gasta en unos días lo que se ahorró durante toda una vida y se muere en medio del dolor y el aislamiento de una tecnologización a menudo trivial e inútil. Se niega el cuidado domiciliario o se lo realiza con descuido e improvisación. A veces, se prolonga la peor de las agonías, la agonía con esperanza, con mentiras piadosas, la distanasia tecnocrática irrelevante. 
Tal vez el papel de la reflexión bioética sea invitar e incitar al diálogo entre personas que honestamente difieren sobre cómo habría que encarar el vivir y el morir dignamente. Reconocer que hay problemas técnicos que ninguna técnica soluciona abre la puerta para los consuelos de la compañía compasiva, del rito aliviador, de la religión como satisfacción de la necesidad de creer y confiar (Christian-Widmaier, 1988).

Examinar estos asuntos está fuera de la intención y los límites de este escrito. Que quede, sin embargo, como una síntesis, la expresión que le otorga título. Los cuidados paliativos, además de toda otra determinación, deben propender a evitar la distanasia tecnocrática, a restablecer la compasión, la dignidad y la solidaridad en el armamentarium de los seres humanos, profesionales y legos, como parte del oficio de vivir y de la inevitable tarea de morir.

\section{Referencias bibliográficas}

(Las referencias a este tema son imposibles de resumir, por lo numerosas y variadas. Entre los documentos accesibles y próximos al contexto latinoamericano procede citar el número monográfico de la revista Acta Bioethica (Año VI, Número 1, 2000), publicada por el Programa regional de Bioética OPS/OMS en Santiago de Chile y disponible en "http://www.bioetica.ops-oms.org/E/docs/actaa.pdf" http://www.bioetica.ops-oms.org/E/docs/actaa.pdf . Allí se encuentran contribuciones y referencias adecuadas.

Como documento técnico de la Organización Panamericana de la Salud cabe mencionar la Guía para el manejo clínico accesible en "http://www.paho.org/Spanish/AD/DPC/NC/palliative-care.pdf" http://www.paho.org/Spanish/AD/DPC/NC/palliative-care.pdf . Este libro resume experiencias propias de la región latinoamericana y brinda una adecuada guía para quienes laboran en servicios de salud. Callahan, D. False Hopes. Simon \& Schuster, New York, 1998.

Christian-Widmaier, P. Krankenhausseelsorger und todkranker Patient. Springer-Verlag, BerlinHeidelberg-New York, 1988.

Drane, J. El cuidado del enfermo terminal (edición de Fernando Lolas Stepke) Publicación Científica $\mathrm{N}^{\circ}$ 573, Organización Panamericana de la Salud, Washington DC, USA, 1999.

Lolas, F. Proposiciones para una teoría de la medicina. Editorial Universitaria, Santiago de Chile, 1992. Lolas, F. La muerte es tema para los vivos: una perspectiva socioética. Anales de la Universidad de Chile, Sexta Series, N 6: 83-90, 1997.

Lolas, F. Nota bioética sobre el paciente crítico. Editorial. Revista Chilena de Cirugía 52(2):113-116, 2000. Lolas, F. Escritos sobre vejez, envejecimiento y muerte. Editorial Campus, Universidad Arturo Prat, Iquique, 2002.

Pessini, L. Bioética y cuestiones éticas esenciales en el final de la vida. En Lolas, F., editor, Diálogo y cooperación en salud. Diez años de bioética en la OPS. Unidad de Bioética OPS/OMS, Santiago de Chile, 2004. 